\title{
El Periodismo y sus fronteras
}

\author{
Francisco Fernández Beltrán \\ Director de Comunicación y Publicaciones y profesor del \\ departamento de Ciencias de la Comunicación de la Universitat Jaume I
}

En medio de un panorama general de crisis -económica, pero también de modelo e incluso de los valores del ejercicio profesional- el Periodismo ensancha sus fronteras y busca nuevos espacios en los que poder desarrollarse. En ese contexto, la frontera que hasta la fecha separaba al periodista que llevaba a cabo su labor en los medios y el que lo hacía en un gabinete de Prensa o de Comunicación se hace cada vez más difusa, y resulta una práctica igual de válida y necesaria la una como la otra. Por ello, esta tribuna profesional se acerca a un fenómeno que tiene una importancia creciente en el actual escenario comunicativo y lo hace de la mano de tres grandes profesionales, que aúnan una amplia experiencia a ambos lados del ejercicio periodístico y que, además, se aproximan a este ámbito profesional desde una perspectiva muy innovadora, la relacionada con su transformación por el auge de las nuevas tecnologías y la de la especialización en campos tan interesantes como los de la comunicación científica y la universitaria.

Así, el primer texto de la periodista Rosa de Bustos analiza la difícil relación entre periodistas de medios y de gabinetes y cómo ésta se ha visto transformada de manera radical por la irrupción de las nuevas tecnologías y el cambio que ha provocado en el ecosistema informativo. En un artículo realmente recomendable, de Bustos expone las claves para la correcta adaptación de los gabinetes de Comunicación a las nuevas fórmulas de información y participación que imponen Internet y, sobre todo, las herramientas comunicativas 2.0. El cambio que ya han experimentado gran parte de los usuarios y muchos de los medios no se ha hecho igual de efectivo entre otros actores, como los gabinetes de Comuni- 
cación. Por ello, de Bustos recomienda al gabinete de prensa surgido en la era digital que sea «el impulsor de la actividad informativa de la organización, no el que la centraliza para monopolizarla». Se hace preciso, pues, un cambio de perspectiva, un cambio de foco, que obligará a las organizaciones a «acostumbrarse a proporcionar a su cada vez más extensa red de seguidores la información también con distintos niveles de profundización». En este nuevo escenario, los gabinetes de Comunicación han de pasar a asumir un papel más protagonista y directo en la información ciudadana, de manera que sean capaces incluso de asumir parte del trabajo de intermediación que hasta la fecha llevaban a cabo los medios y que ahora no es necesario.

En el segundo texto, la periodista María Jesús Cañellas, exsubdirectora de Informe Semanal, nos muestra la complejidad del ejercicio periodístico en el ámbito científico, un terreno en el que, nuevamente, vemos el importante papel que tienen que jugar los periodistas que trabajan en las organizaciones, en este caso científicas. Como apunta Cañellas, el periodismo científico exige un esfuerzo de síntesis muy complicado y «para conseguirlo, es fundamental el trabajo de los gabinetes de Comunicación». Se trata de una labor de gran dificultad y que, al mismo tiempo, es cada vez más demandada por parte de una sociedad conocedora de la importancia de estar al corriente de los avances de la ciencia en su vida cotidiana. La comunicación científica, como acertadamente apunta la periodista, es un deber para los científicos y un derecho para los ciudadanos, aunque para logarlos ambos tengan que apoyarse de manera decidida en el papel mediador de los periodistas, tanto de los que trabajan en los medios como de los que lo hacen en los gabinetes.

Y del papel de los gabinetes de Comunicación en las organizaciones científicas, pasamos a unas muy concretas, las universidades, que aúnan a esa labor de investigación la actividad docente y cultural. Antonio Marín, periodista que estuvo al frente durante años del Servicio de Comunicación de la Universidad de Granada, nos muestra claramente los retos a los que se han de enfrentar los profesionales que desarrollan su actividad en este terreno, sobre todo debido a la expansión absoluta de las nuevas tecnologías de la información y, de manera muy particular, de la web 2.0 o web social. Marín nos muestra acertadamente cómo han de replantearse su labor los gabinetes de Comunicación universitarios, en especial en cuanto a qué públicos, de qué manera y con qué canales han de comunicarse con los mismos.

Por último, la sección se cierra con dos reseñas de sendas novedades bibliográficas. Por un lado, Fátima Ramos describe el contenido de la última obra que han coordinado por los profesores Javier Marzal y Andreu Casero, y en la que nos muestran las últimas tendencias del periodismo en televisión. Asimismo, contamos con un texto sobre el libro más reciente del profesor Fernando Olivares, de la Universidad de Alicante, que analiza el fenómeno creciente de las marcas blancas o marcas de distribuidor, que resulta de especial interés en el ámbito del periodismo económico. 


\section{Referencia de este artículo:}

Fernández Beltrán, Francisco (2012). El Periodismo y sus fronteras. En: adComunica. Revista Científica de Estrategias, Tendencias e Innovación en Comunicación, $\mathrm{n}^{\circ}$ 4. Castellón: Asociación para el Desarrollo de la Comunicación adComunica, Universidad Complutense de Madrid y Universitat Jaume I, 219-221. DOI: http://dx.doi.org/10.6035/2174-0992.2012.4.13 